\title{
Pola Kuman, Sensitifitas Antibiotik dan Risiko Kematian oleh Kuman Staphylococcus coagulase Negatif pada Sepsis Neonatorum di RS DR Moewardi Surakarta
}

\author{
Yulidar H, Sri Martuti, Sunyataningkamto
}

Latar belakang. Sepsis neonatorum merupakan penyebab kematian tertinggi pada neonatus. Sebagai pedoman antibiotik yang akan diberikan diperlukan data pola kuman secara berkala. Beberapa Negara telah melaporkan infeksi Staphylococcus coagulase negative (CoNS) yang merupakan kuman komensal kulit, sebagai penyebab sepsis neonatorum awitan lambat.

Tujuan. Penelitian ini bertujuan untuk mengetahui pola kuman dan jenis antibiotik yang sensitif pada bayi sepsis yang dirawat di bangsal neonatus RS Dr. Moewardi Surakarta dan risiko kematian oleh Staphylococcus coagulase negatif (CoNS).

Metoda. Penelitian dilakukan secara retrospektif dengan mengambil data dari rekam medis bayi yang dirawat di bangsal neonatus RS Dr. Moewardi (RSDM) Surakarta. Data diambil dari bulan Desember 2004 sampai Desember 2005 dengan diagnosis sepsis, didapatkan hasil kultur kuman positif.

Hasil. Didapatkan 49 data dengan kuman positif. Kuman penyebab sepsis didapatkan berturut-turut Enterobacter sebagai penyebab terbanyak 42,9\%, diikuti oleh Staphylococcus dan Citrobacter masing-masing 18,4\%, Streptococcus dan Serratia 6,1\%, Pseudomonas dan Klebsiella 4,1\%. Pada kelompok kuman Enterobacter meropenem merupakan antibiotik dengan sensitifitas paling tinggi $(73,7 \%)$ dan sensitifitas terhadap sefepim 38,1\%. Angka kematian secara keseluruhan 57,1\%. Pada kelompok kuman Enterobacter, Staphylococcus dan Citrobacter angka kematian berturut-turut $57,1 \%, 33,3 \%$ dan $77,8 \%$. Risiko kematian oleh kuman CoNS dibandingkan dengan kuman gram negatif RR 5,5 dengan tingkat kepercayaan 95\% $(0,97 ; 31,45)$. Risiko kematian terhadap Staphylococcus aureus juga tidak berbeda bermakna.

Kesimpulan. Kuman yang paling sering ditemukan pada bayi sepsis di bangsal neonatus RSDM Surakarta adalah Enterobacter. Angka kematian masih tinggi 57,1\% dan tidak terdapat perbedaan bermakna pada risiko kematian CoNS dibandingkan dengan kuman gram negatif dan Staphylococcus aureus.

Kata kunci: sepsis, bayi, antibiotik, Enterobacter, Staphylococcus

Alamat korespondensi:

Dr. Yulidar H, SpA. SMF Penyakit Anak RS.Dr.Muwardi/ Lab.IKA FK UNS Fax: (0271)-664598 Surakarta (57132) (0271) 728123

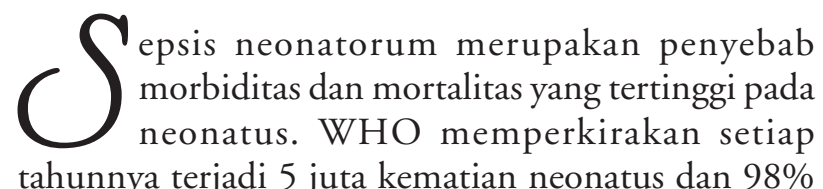

tahunnya terjadi 5 juta kematian neonatus dan $98 \%$ 
terjadi di negara berkembang. Penyebab kematian utama pada neonatus tersebut adalah infeksi, prematuritas dan asfiksia pada bayi baru lahir. Pada bayi prematur sepsis dihubungkan dengan belum matangnya sistem kekebalan, keadaan dasar yang berat dan sering dilakukannya prosedur invasif seperti pemasangan kateter vena dan arteri umbilikus maupun vena sentral. Angka kejadian sepsis di negara berkembang masih cukup tinggi berkisar 1,8-18/ 1000 dibanding negara maju 4-5/1000 kelahiran. Di Rumah Sakit Cipto Mangunkusumo (RSCM) dalam periode Januari-September 2005, angka kejadian sepsis neonatorum sebesar $13,68 \%$ dari seluruh kelahiran hidup dengan tingkat kematian sebesar 14,8\%. ${ }^{1}$ Angka kejadian dan mortalitas sepsis neonatorum di RSDM Surakarta belum pernah dilaporkan. Penyebab sepsis neonatorum pada beberapa penelitian berbeda antar negara maupun antar waktu. Staphylococcus coagulase negative (CoNS) yang merupakan kuman komensal di kulit kini banyak dilaporkan sebagai penyebab sepsis neonatorum awitan lambat, meskipun mortalitasnya rendah. ${ }^{2-6}$ Di beberapa RS Pendidikan di Indonesia didapatkan Acinebacter, Enterobacter dan Pseudomonas sebagai penyebab tersering sepsis neonatorum. ${ }^{1,7}$

Pemberian antibiotik yang tepat pada sepsis neonatorum akan menurunkan risiko kematian, jenis antibiotik yang diberikan seharusnya sesuai dengan hasil uji kepekaan kuman. Sampai saat ini pemeriksaan kultur dan uji kepekaan kuman yang ada masih memerlukan waktu yang lama, sedangkan keterlambatan penatalaksanaan sepsis neonatorum akan meningkatkan mortalitasnya. Di sisi lain pemberian antibiotik yang tidak sesuai dengan kuman penyebab akan menimbulkan super infeksi oleh bakteri multi resisten dan jamur. ${ }^{6}$ Pola kuman setempat dengan hasil uji kepekaan kuman yang ada dapat dipakai sebagai dasar pemberian antibiotik secara empiris. Divisi Perinatologi RSDM sampai saat ini masih menggunakan kombinasi ampisilin dan gentamisin untuk tatalaksana sepsis neonatorum sambil menunggu hasil biakan kuman. Pola kuman dan uji kepekaan kuman di bangsal neonatus RSDM belum pernah diteliti, demikian juga dengan risiko kematian oleh CoNS yang merupakan kuman komensal di kulit, diharapkan hasil penelitian ini dapat dijadikan sebagai evaluasi pemberian antibiotik pada sepsis neonatorum dan pengambilan kebijakan pemberian antibiotik empiris di masa mendatang.

\section{Metoda}

Penelitian ini merupakan penelitian retrospekstif dengan mengambil data dari rekam medis bayi yang dirawat di bangsal neonatus RSDM Surakarta antara Desember 2004 sampai dengan Desember 2005, dengan diagnosis sepsis neonatorum. Kriteria diagnosis sepsis neonatorum didasarkan pada tanda klinis, hipotermia atau hipertermia, gangguan pernapasan (takipneu, merintih, apneu), sianosis, takikardia, malas minum, residu lambung, atau perut distensi. ${ }^{4,7}$ Subyek penelitian ini adalah semua bayi sepsis dengan data rekam medis lengkap, didapatkan hasil kultur dan uji kepekaan kuman. Data yang didapatkan diolah dengan program SPSS 10 untuk mengetahui persentase jenis kuman penyebab sepsis neonatorum dan persentase sensitifitas beberapa jenis antibiotik yang sering digunakan dalam penatalaksanaan sepsis neonatorum. Antibiotik tersebut yaitu ampisilin, gentamisin, amikasin, cefotaksim, ceftazidim, cefepime, dan meropenem. Risiko kematian dari masing-masing kuman penyebab dianalisis, hasil ditampilkan dalam rasio risiko dan tingkat kepercayaan $95 \%$.

\section{Hasil Penelitian}

Selama periode Desember 2004 sampai Desember 2005 didapatkan 49 kasus sepsis neonatorum dengan hasil kultur dan uji kepekaan kuman. Jenis kuman penyebab sepsis neonatorum tertera pada Gambar 1 . Enterobacter merupakan penyebab terbanyak 42,9\%, diikuti oleh Staphylococcus dan Citrobacter masingmasing 18,4\%, Streptococcus dan Serratia 6,1\%, Pseudomonas dan Klebsiella 4.1\%. Terdapat 9 spesimen positif Staphylococcus terdiri dari 8 spesimen CoNS dan 1 spesimen Staphylococcus aureus.

Pada kelompok kuman enterobacter, meropenem merupakan antibiotik dengan sensitifitas paling tinggi $(73,7 \%)$ dan sensitifitas terhadap cefepime $38,1 \%$. (Tabel 1) Antibiotik yang lain yaitu amikasin, cefotaksim, ampisilin, ceftazidim dan gentamisin merupakan antibiotik dengan sensitifitas sangat rendah.

Pada kelompok kuman Staphylococcus, antibiotik amikasin, meropenem, dan sefepim memiliki sensitifitas paling tinggi (25\%), sefotaksim dan ampisilin berturut-turut $11,1 \%$ dan $12,5 \%$, terhadap antibiotik lain telah resisten. Pada kelompok kuman Citrobacter, meropenem memiliki sensitifitas 100\%, 

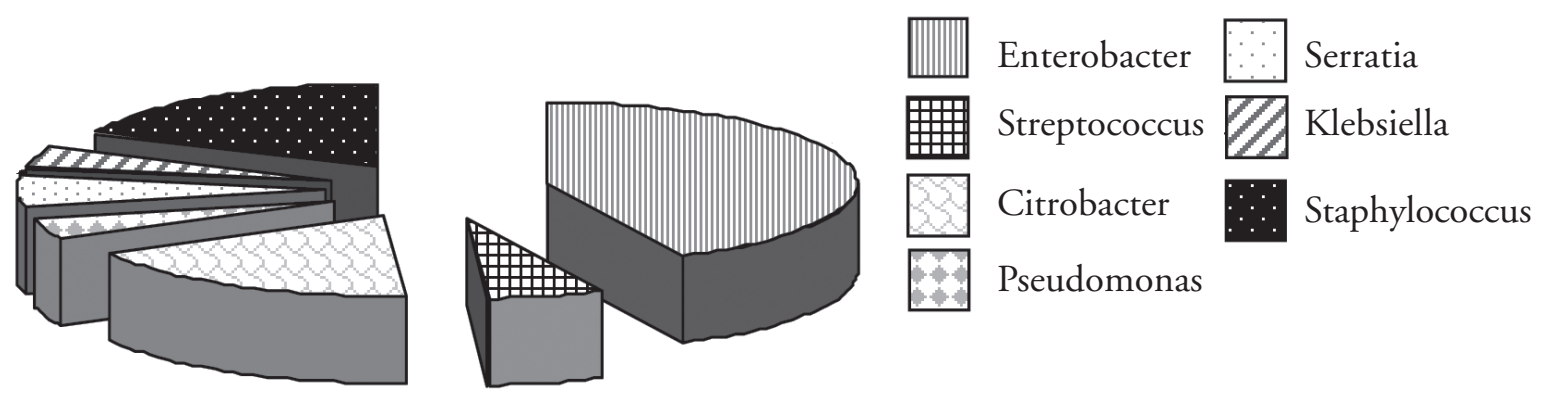

2 Pseudomonas

Gambar 1. Kuman penyebab sepsis neonatorum di RS Dr. Moewardi Surakarta, 2004-2005

Tabel 1. Sensitifitas antibiotik terhadap infeksi oleh Enterobacter, Staphylococcus, dan Citrobacter

\begin{tabular}{lcccccc}
\hline Jenis antibiotik & \multicolumn{2}{c}{ Enterobacter } & \multicolumn{2}{c}{ Staphylococus } & \multicolumn{2}{c}{ Citrobacter } \\
& $\mathrm{R}(\%)$ & $\mathbf{S}(\%)$ & $\mathrm{R}(\%)$ & $\mathrm{S}(\%)$ & $\mathrm{R}(\%)$ & $\mathrm{S}(\%)$ \\
\hline Ampisilin & 100 & 0 & 87,5 & 12,5 & 100 & 0 \\
Amikasin & 90,5 & 9,5 & 75 & 25 & 100 & 0 \\
Cefotaksim & 100 & 0 & 88,9 & 11,1 & 100 & 0 \\
Ceftazidim & 100 & 0 & 100 & 0 & 100 & 0 \\
Meropenem & 26,3 & 73,3 & 75 & 25 & 0 & 100 \\
Gentamisin & 100 & 0 & 100 & 0 & 100 & 0 \\
Cefepime & 61,9 & 38,1 & 75 & 25 & 11,1 & 88,9 \\
\hline
\end{tabular}

Keterangan: R: Resisten S: Sensitif $n=49$

sefepim $88,9 \%$, sedangkan antibiotik lain telah resisten.

Angka kematian secara keseluruhan 57,1\%, pada kelompok kuman Enterobacter, Staphylococcus dan Citrobacter berturut-turut 57,1\%, 33,3\% dan 77,8\%. Risiko kematian oleh kuman CoNS tidak berbeda bermakna dibandingkan dengan kuman Gram negatif (RR 5,5; tingkat kepercayaan 95\% 0,97;31,45), demikian juga jika dibandingkan dengan Staphylococcus aureus.

\section{Diskusi}

Pola kuman akan berbeda antar negara dan berubah dari waktu ke waktu. Penelitian ini mendapatkan Enterobacter 21 pasien sebagai kuman penyebab tersering sepsis neonatorum di bangsal neonatus RSDM Surakarta, diikuti oleh Staphylococcus dan Citrobacter masing-masing 9 pasien. Penelitian di negara maju akhirakhir ini mendapatkan CoNS sebagai kuman yang tersering ditemukan pada biakan darah terutama pada sepsis awitan lambat. Rubin LG dkk. ${ }^{5}$ mendapatkan hasil biakan positif CoNS 54\%, sedangkan Isaacs D $\mathrm{dkk}^{3}$ mendapatkan episode sepsis oleh CoNS 57,1\%. Penelitian yang dilakukan oleh Karlowitz MG mendapatkan sepsis fulminan paling sering terjadi pada kelompok Pseudomonas $s p$ dan paling jarang pada CoNS. ${ }^{8}$ Suarca K di RS Sanglah, Denpasar mendapatkan hasil yang sama dengan penelitian ini yaitu Enterobacter $s p$ sebagai penyebab tersering sepsis neonatorum awitan

Tabel 2. Prognosis berdasarkan kuman penyebab sepsis

\begin{tabular}{lccc}
\hline \multirow{2}{*}{ Jenis kuman } & \multicolumn{2}{c}{ Prognosis } & \multirow{2}{*}{ total } \\
\cline { 2 - 3 } & hidup & kematian & \\
\hline Enterobacter sp & 9 & 12 & 21 \\
Citrobacter sp & 2 & 7 & 9 \\
Staphylococcus coagulase & & & \\
negatif & 6 & 2 & 8 \\
Streptococcus sp & 2 & 1 & 3 \\
Serratia sp & 0 & 3 & 3 \\
Pseudomonas sp & 2 & 0 & 2 \\
Klebsiella sp & 0 & 2 & 2 \\
Staphylococcus aureus & 0 & 1 & 1 \\
\hline
\end{tabular}


dini dan CoNS pada sepsis awitan lambat. ${ }^{9}$ Di RSCM Jakarta tahun 1975-1980 kuman penyebab sepsis berturut-turut Salmonella $s p$ dan Klebseilla sp, pada tahun 1985-1990 Klebseilla tetap menempati urutan kedua dengan Pseudomonas sebagai penyebab utama, sedangkan tahun 1995-2003 terjadi perubahan total, Klebseilla bukan lagi menjadi kuman penyebab, tetapi pola kuman berubah berturut-turut Acinebacter sp, Enterobacter $s p$, Pseudomonas $s p$ dan Serratia $s p .{ }^{1}$ Penelitian yang dilakukan oleh Imran $M$ dkk di Palembang pada tahun 2001 mendapatkan Acinebacter dan Pseudomonas sebagai kuman penyebab tersering. ${ }^{4}$ Penelitian ini tidak membedakan sepsis awitan dini dan awitan lambat, dan sampai saat ini Subdivisi Perinatologi RSDM Surakarta belum memisahkan antara bayi-bayi yang dilahirkan di lingkungan RSDM dengan yang dikirim dari fasilitas persalinan di luar RS, sehingga pola kuman ini belum menggambarkan pola kuman pada sepsis awitan dini atau awitan lambat. Pola kuman pada bayi sepsis yang berasal dari luar RS juga belum dapat dinilai.

Meropenem merupakan antibiotik dengan sensitifitas paling tinggi pada semua kelompok kuman penyebab. Sensitifitas terhadap meropenem pada kelompok kuman Enterobacter, Staphylococcus dan Citrobacter berturut-turut $73,7 \%$, 25\% dan 100\%, sedangkan sensitivitas terhadap sefepim 38,1\%, 25\% dan $88,9 \%$. Sensitivitas terhadap antibiotik yang lain rendah. Antibiotik yang selama ini dijadikan pilihan empiris pada sepsis neonatorum di RSDM Surakarta yaitu ampisilin memiliki resistensi yang tinggi, bahkan resistensi terhadap gentamisin mencapai $100 \%$. Berbeda dengan hasil penelitian ini, di RS Mohammad Hoesni, Palembang didapatkan seftazidim lebih efektif dibandingkan kombinasi ampisilin dengan gentamisin, pada penelitian ini ceftazidim ternyata juga memiliki resistensi yang cukup tinggi. ${ }^{4}$

Akhir-akhir ini di negara maju didapatkan prevalensi CoNS sebagai sepsis meningkat namun angka kematian rendah. Isaacs D yang melakukan penelitian selama 10 tahun mendapatkan 1281 kasus sepsis disebabkan oleh CoNS dengan angka kematian $1,9 \%$. Isaacs D juga mendapatkan risiko kematian oleh CoNS pada sepsis awitan lambat secara bermakna lebih rendah dibandingkan dengan Staphylococcus aureus RR 36,1 (95\%CI:13,0-100,2), demikian juga terhadap bakteri Gram negative RR 45,5(95\%CI:16,8-123,3). ${ }^{3}$ Pada penelitian ini kematian oleh CoNS cukup tinggi yaitu 2 dari 8 pasien. Risiko kematian oleh kuman
CoNS dibandingkan dengan kuman Gram negatif dan Staphylococcus aureus ternyata tidak berbeda. Perbedaan hasil tersebut kemungkinan karena; pertama kemungkinan kematian pada kelompok kuman CoNS tidak semata-mata disebabkan oleh infeksi CoNS tetapi disebabkan beberapa faktor risiko seperti berat badan lebih rendah, prematuritas, awitan sepsis dan komplikasi. Kedua, perbedaan tata laksana pasien. Penelitian ini melibatkan subyek yang dirawat swadana maupun askes gakin (askes untuk keluarga miskin). Pemberian antibiotik maupun terapi pendukung lain pada kelompok subyek swadana selalu tersedia sedangkan dari kelompok askesgakin harus menunggu protokol. Ketiga, kemungkinan besar disebabkan sampel penelitian terlalu kecil jika dibandingkan dengan penelitian oleh Isaac D.

\section{Kesimpulan}

Kuman yang paling sering ditemukan pada sepsis neonatorum di bangsal neonatus RSDM Surakarta adalah Enterobacter. Meropenem merupakan antibiotik dengan sensitivitas tertinggi, pilihan kedua adalah sefepim. Gentamisin tidak dapat digunakan sebagai terapi empiris karena memiliki resistensi tertinggi. Angka kematian sepsis neonatorum oleh berbagai kuman penyebab di RSDM masih tinggi dan risiko kematian oleh CoNS tidak berbeda bermakna dibandingkan dengan kuman Gram negatif maupun Staphylococcus aureus.

\section{Saran}

Perlu dilakukan penelitian dengan besar sampel lebih besar dan melakukan analisis terhadap faktor-faktor yang berpengaruh terhadap kematian bayi sepsis.

\section{Daftar Pustaka}

1. Aminullah A. Masalah terkini sepsis neonatorum. Dalam: Badriul Hegar S, Partini P. Trihono, Evita Bemanshah Ifran, penyunting. Update in neonatal infection. PKB IKA FKUI XLVIII. Penerbit, Jakarta: Balai Penerbit FKUI; 2005.h. 1-15

2. Vergagno S, Sharland M, Kazembe P. Neonatal sepsis : an international perspective. Arch Dis Child 2005; 90:F220-4. 
3. Isaacs D. A ten year, multicentre of coagulase negative staphylococcal infectios in Australian neonatal units. Arch Dis Child 2003;88:F89-93.

4. Imran M, Tasli J, Bermawi H. Perbandingan efektifitas kombinasi ampisilin dan gentamisin dengan seftazidim pada pengobatan sepsis neonatorum. Sari Pediatri 2001;3:92-100.

5. Rubin LG, Sanchez PJ, Siegel J. Evaluation and treatment of neonates with suspected late-onset sepsis: a survey of neonatologists practices. Pediatrics 2002;110: $1-7$.

6. Center KJ, Reboli AC, Hubler R. Decreased vancomycin susceptibility of coagulase-negative Staphylococci in a neonatal intensive care unit: evidence of spread of Staphylococcus warneri. J Clin Micro 2003;41: 4660-5.

7. Machado JKK, Feferbaum R, Diniz EMA. Monitoring the treatment of sepsis with vancomycin in term newborn infants. Rev. Hosp Clin Fac Med S Paulo 2001;56:17-24.

8. Karlowitz MG, Buescher SE, Surka AE. Fulminant late onset sepsis in neonatal intensive care unit, 1988-1997, and the impact of avoiding empiric vancomycin therapy. Pediatrics 2000;106:1386-90.

9. Suarca K, Kardana M, Iswari IS. Blood culture and sensitivity test pattern of early versus late onset sepsis in neonatal ward Sanglah Hospital Denpasar. Abstract Book. KONIKA XIII. Bandung 2005. 